\title{
Food Choice Behaviour of Chinese Consumers in Shenyang, Liaoning Province
}

\author{
Roseline Love MacArthur1, Yuehua Wang1, Xuqiao Feng2* \\ ${ }^{1}$ College of Food Science, Shenyang Agricultural University, Shenyang, China \\ ${ }^{2}$ Food Science Research Institute of Bohai University, Food Safety Key Lab of Liaoning Province, Jinzhou, China \\ Email: macarthur652000@yahoo.com, wangyuehua20122132@163.com, ${ }^{*}$ feng xq@hotmail.com
}

Received 11 June 2015; accepted 29 August 2015; published 1 September 2015

Copyright (C) 2015 by authors and Scientific Research Publishing Inc.

This work is licensed under the Creative Commons Attribution International License (CC BY). http://creativecommons.org/licenses/by/4.0/

(c) ()

\section{Abstract}

The aim of the study was to investigate consumers' use of nutrition claims and to determine the food choice behaviour of Chinese consumers based on the nutrient content of packaged foods. A cross-sectional descriptive research approach was followed. Combined stratified and random sampling methods were used to select $\mathbf{4 0 0}$ adult literate consumers involved in packaged food purchases from international chain supermarkets and other popular shops in Shenyang in Liaoning Province, North-East of China. Data were collected with questionnaires and analysed with both descriptive and inferential statistics. The results indicated that none of the respondents could interpret "salt free", only $6.0 \%$ understood "reduced sugar" and $70 \%$ were sceptical about such claims. A total of $53.8 \%$ and $64.4 \%$ of the respondents neither understood the term or knew their RDA respectively, even though familiarity with these had implication for food consumption. Respondents' use of information on calorie $($ Mean $=3.003$, Std. Dev. $=1.248)$, sugar $($ Mean $=3.151$, Std. Dev. $=1.175)$ and fat $($ Mean $=3.175$, Std. Dev. $=1.202)$ content affected their food choices "sometimes" while salt content "rarely" (Mean $=2.803$, Std. Dev. $=1.193$ ) did. While the highest level education showed no significance, health status was significantly and negatively correlated with low-calorie $(r=-0.094, p<0.01)$ and low-salt $(r=-0.083, p<0.05)$ food choices. Taste influenced the choice of biscuits/cookies, which normally had high amount of fat, sugar and/or salt. The findings suggested a low nutrition labelling awareness even though majority of the respondents were well educated. Misconception and scepticism about label claims and value placed on taste could lead to over consumption of the negative nutrients from packaged foods. Consumer education and enforcement of claims on calorie, fat, sugar and salt are emphasized.

\section{Keywords}

Nutrition Labelling Awareness, Food Choice Behaviour, Negative Nutrition Factors, China

\footnotetext{
${ }^{*}$ Corresponding author.
} 


\section{Introduction}

Unhealthy diets have been noted as a risk factor for non-communicable diseases [1], currently posing both personal and public health concerns due to the prevalence rates worldwide and the associated economic burden in terms of healthcare [2]. Current scientific evidence suggests that there is a need for individuals to modify their nutrient intake in order to prevent chronic disease that is confronting the entire globe [1]. WHO [1] advocates that individuals consume foods that are low in saturated fat, trans-fatty acids, free sugars and salt. Recognizing that appropriate diet has a considerable effect on society's health improvement and the fact that nutrition labels shape consumers eating behaviour, a worldwide campaign has been launched to help enforce rigorous guidelines to ensure that good and adequate nutrition information is made available to individuals [1]. This initiative has provoked interest in nutrition labelling and consumers all over the globe are beginning to demand label information on the nutrition of the food they are eating.

Nutrition information on food labels is a means by which nutrition information is made available to consumers at the point of purchase [3] to guide them make informed food choices. While the prevalence of nutrition labelling is far advanced in some developed countries, such as Australia, New Zealand and United States [4]-[6], other countries with developing economies are either constantly re-examining and developing new labelling provisions [7] [8] or have just taken a bold step to publish comprehensive nutrition labelling legislation [9]. All these efforts at nutrition labelling are to facilitate informed consumer food choice. In China, the provision of nutrition information started in 2008 when Ministry of Health of the People's Republic of China [10] launched the new nutrition labelling regulations. The move was the first step, by the Chinese government, to normalize the labelling environment at the national policy level and also to comply with international guidelines in an attempt to help reduce the risk of chronic diseases through unhealthy diets. Per the regulation, food manufacturers are encouraged to identify nutrition information panel, nutrition claims, and nutrient function claims in addition to the general food labelling on labels of all products meant for sale. In stating the nutrient content of products, manufacturers are required to include information on calories and four core nutrients: protein, carbohydrate, fat, and sodium to allow consumers make choices that limit the intake of these nutrients.

A survey and a follow up study were carried out after the implementation of the nutrition labelling regulation in 2008 and 2010. The aim was to examine the prevalence of nutrient declaration and nutrition claims of some ingredients, including fats, sugars, and sodium, in packaged foods in Hangzhou, China and to ascertain whether there had been changes in compliance levels two years after the implementation of regulation [11] [12]. Findings suggested that compliance with regulation was not to the mark even though the level of normalization for nutrition labelling had improved remarkably after two years of implementation. The authors suggested government steps up measures to ensure that all manufacturers comply fully with the new nutrition labelling regulation. Lv et al. [12] concluded from their survey that Chinese consumers knowingly perused the mandatory general food labelling, such as manufacturing date and shelf life, when buying packaged food products. The authors also indicated a lack of data on consumers' knowledge and utilization of nutrition labelling, which was at its initial stages and voluntary too. Furthermore, regardless the low prevalence of nutrition labelling, Wang et al. [11] alleged that the Chinese public as well as food manufacturers did not give due recognition to calories, fats, sugars, and sodium content of packaged foods and highlighted the need for the development of comprehensive nutrition education campaigns to support the nutrition labelling policy. Informed and operational nutrition education programs can only be developed through research that examines the role of such claims on consumer purchasing and food consumption behaviour. This therefore calls for an investigation into consumers' nutrition labelling awareness, understanding of nutrition claims and actual consumer behaviour, which will provide the basis for the development of nutrition education, the management of nutrition labelling policy and for making decisions on the development of food products [7].

This study therefore aimed to provide data on nutrition labelling awareness, understanding of nutrition claims, and whether claims on calories, fat, sugar and salt guided consumers living in Shenyang in the Liaoning province of China, to take the right decisions when buying packaged foods. It is hoped that the results of this study will add to the modest data on the use and understanding of nutrition labels and provide useful information for both manufacturers and regulators to assist in evaluating the impact of the nutrition labelling on consumer food choices in China. Findings will also create awareness, contribute to the facilitation of label reading in the region and motivate consumers to modify dietary behaviour with regard to the negative nutrition factors. 


\section{Material and Methods}

\subsection{Selection of Subjects}

A cross-sectional and descriptive research approach was followed. Purposive sampling was used to identify Shenyang, the capital and the largest city of Liaoning Province and an urban and a multi-ethnic settlement. Supermarkets, department stores and shopping malls were chosen as the appropriate site for data collection, since consumers encounter food labels during the purchasing of food products. A list of all international chain supermarkets and other popular shops that sell daily consumer goods in Shenyang, China was procured online. The shops comprised four Carrefour stores, two Tesco shops, two Department stores and two Malls.

The shopping centres were first stratified according to type and location. The names of the shopping centres in each stratum were written on paper and placed in a bowl. One shop each was randomly selected from each stratum. The procedure resulted in a fair selection of shopping centres across location and type and represented $40 \%$ of large shopping centres in Shenyang. Four hundred customers (100 from each shopping centre) who were 20 years or older and involved in the purchasing of household food products were randomly drawn from the selected shops to participate in the study.

\subsection{Data Collection}

The self-administered questionnaire used for the study was first developed in English and carefully translated from English into Chinese by a native speaker with relevant research expertise and proficient in both languages. The translated questionnaire was then back-translated to English by another native speaker and again reviewed by a professor who is an expert in both languages, to ensure that there was no deviation from the original text and the information in both languages conveyed the same message. Slight differences between both translations were discussed and adapted when appropriate.

The questionnaire was pilot tested using 20 respondents who were qualified to be part of the study population but sampled from small shops in the same city. This helped to test readability and ensure that the questionnaire was comprehensible and of reasonable length, in order not to discourage respondents from participating in the study, since the questionnaire had to be completed on the spot. These evaluations resulted in some minor changes for a couple of question items and helped to estimate the time respondents may require completing the questionnaire.

The questionnaire covered respondents' demographic and situational characteristics, nutrition awareness and influence of nutritional claims on consumers' food choices. To test their nutrition awareness, respondents' were presented with three label claims on fat, sugar and salt, which they were required to select responses from given options. Their understanding of recommended dietary allowances and knowledge about their individual dietary energy and nutrients needs were also sought. The third part of the questionnaire examined the influence of calorie and the negative nutrition factors on their food choices.

\subsection{Statistical Analysis}

Data were analysed using the Predictive Analytic Software (PASW) version 19.0. Frequency and percentage distributions were used to analyse data on the background characteristics and respondents' understanding of label information. Food purchasing habits items, which were on four-point Likert scale, were scored numerically to reflect hierarchy or intensity and Means and Standard deviations were calculated for the scores. Pearson's correlation coefficients were used to assess the correlation between internal factors and food purchasing behaviour while independent t-test for comparing the food purchasing behaviour of male and female respondents. Statistical results were considered to be significant at $\mathrm{p}<0.05$.

\section{Results}

More than half (55\%) of the respondents were males with close to one third (30.8\%) between the ages of 20 and 30 years. About $48.3 \%$ of the sample was married and a total of $34.3 \%$ had attained a tertiary education reflecting higher educational level among shoppers questionnaires were administered on. The level of education of the sample was reflected on their occupations; as $37 \%$ were government employees; $23.5 \%$ were self-employed, $12.5 \%$ were students and $11.5 \%$ were working in the private sector. About two thirds (61.5\%) had a fair nutri- 
tion knowledge, suggesting that level of education may not correlate with nutrition knowledge, while a preponderant percentage (86\%) had no health condition (Table 1).

When asked whether or not they read nutrition labels, 79\% responded "yes”. When asked if they understand nutrition information they read, more than three quarters (79.5) of the respondents claimed they "somehow" understand the information with only $7.2 \%$ indicating they "do not understand". To verify respondents' understanding of label information, they were presented with three nutrition claims on the three nutrients associated with chronic diseases to interpret. Just over one third (36.0\%) and only 6.0\% could interpret correctly "low fat" and "reduced sugar" claims respectively, while none of the respondents could interpret "salt free" claim (Table 2).

With respect to the perceived trustworthiness of various claims on food labels, $70 \%$ of the respondents declared that they do not believe label claims. Information regarding understanding of the term "recommended dietary allowances" (RDA), respondents' knowledge about their RDA and whether they selected foods within the

Table 1. Internal factors of respondents $(\mathrm{N}=400)$.

\begin{tabular}{|c|c|c|}
\hline Variable & Frequency & Percentage \\
\hline \multicolumn{3}{|l|}{ Sex } \\
\hline Male & 220 & 55.0 \\
\hline Female & 180 & 45.0 \\
\hline \multicolumn{3}{|l|}{ Age } \\
\hline $20-30$ & 123 & 30.8 \\
\hline $31-40$ & 111 & 27.8 \\
\hline $41-50$ & 97 & 24.3 \\
\hline $51+$ & 69 & 17.3 \\
\hline \multicolumn{3}{|l|}{ Marital status } \\
\hline Never married & 140 & 35.0 \\
\hline Married & 193 & 48.3 \\
\hline Separated & 41 & 10.3 \\
\hline Divorced & 26 & 6.5 \\
\hline \multicolumn{3}{|l|}{ Highest education } \\
\hline None & 3 & 0.8 \\
\hline BECE & 48 & 12.0 \\
\hline SSCE & 100 & 25.0 \\
\hline Diploma & 112 & 28.0 \\
\hline Tertiary & 137 & 34.3 \\
\hline \multicolumn{3}{|l|}{ Employment status } \\
\hline Student & 50 & 12.5 \\
\hline Unemployed & 62 & 15.5 \\
\hline Self-employee & 94 & 23.5 \\
\hline Government employee & 148 & 37.0 \\
\hline Private employee & 46 & 11.5 \\
\hline \multicolumn{3}{|l|}{ Nutrition knowledge } \\
\hline Fair & 246 & 61.5 \\
\hline Good & 86 & 21.5 \\
\hline Very good & 46 & 11.5 \\
\hline Excellent & 22 & 5.5 \\
\hline \multicolumn{3}{|l|}{ Health status } \\
\hline Diabetic & 8 & 2.0 \\
\hline Hypertensive & 27 & 6.8 \\
\hline Heart diseases & 21 & 5.3 \\
\hline None & 344 & 86.0 \\
\hline
\end{tabular}


Table 2. Nutrition knowledge and interpretation of nutrition claims.

\begin{tabular}{|c|c|c|}
\hline Understanding of label information & Frequency & Percentage \\
\hline \multicolumn{3}{|l|}{ Self-perceived level of understanding } \\
\hline Very well & 53 & 13.2 \\
\hline Somehow & 318 & 79.5 \\
\hline Don't understand & 29 & 7.2 \\
\hline \multicolumn{3}{|l|}{ Low fat claim } \\
\hline Less than 2 g per serving & 137 & 34.2 \\
\hline Less than 3 g per serving & 144 & 36.0 \\
\hline Less than 4 g per serving & 30 & 7.5 \\
\hline Less than 5 g per serving & 23 & 5.8 \\
\hline Do not know & 66 & 16.5 \\
\hline \multicolumn{3}{|l|}{ Salt free claim } \\
\hline No salt & 240 & 60.0 \\
\hline $0.1 \mathrm{~g}$ & 131 & 32.8 \\
\hline $0.2 \mathrm{~g}$ & 23 & 5.8 \\
\hline $0.4 \mathrm{~g}$ & 3 & 0.7 \\
\hline $0.5 \mathrm{~g}$ & 0 & 0.0 \\
\hline Do not know & 3 & 0.7 \\
\hline \multicolumn{3}{|l|}{ Reduced sugar claim } \\
\hline At least $10 \%$ less than original item & 233 & 58.2 \\
\hline At least $15 \%$ less than original item & 57 & 14.2 \\
\hline At least $20 \%$ less than original item & 76 & 19.0 \\
\hline At least $25 \%$ less than original item & 24 & 6.0 \\
\hline Do not know & 10 & 2.5 \\
\hline
\end{tabular}

context of their overall daily meals were also sought (not presented in tables). A total of 53.8\% did not know about the term, 64.4\% did not know or were not sure about their daily requirement and $55.5 \%$ did not select foods to reflect what they needed daily. This presupposes that majority of the respondents did not place calories and nutrients consumed from packaged foods within daily total requirements.

Means and Standard deviations of respondents' nutrition label reading and food purchasing behaviours are shown in Table 3. The results show that respondents read nutrition information "sometimes" (Mean = 3.349, Std. Dev. = 1.074) and "sometimes" (Mean = 2.979, Std. Dev. = 1.015) considered the information too technical. Frequency of reading the nutrition information on calorie $($ Mean $=3.003$, Std. Dev. = 1.248) sugar $($ Mean $=$ 3.151, Std. Dev. = 1.175) and fat $($ Mean = 3.175, Std. Dev. = 1.202) “sometimes” affected respondents' purchase decisions while the amount of salt in products "rarely" (Mean $=2.803$, Std. Dev. $=1.193$ ) did irrespective of how often that information was used.

More than two thirds (79.5\%) of respondents indicated that taste was the major determinant when purchasing biscuits/cookies. This was followed by ingredients (58.8\%) and price (58.8) with nutrition label (35.2\%) placing third out of the seven factors. Brand (9.5\%) attracted the least score (Table 4).

The results on the relationship between respondents' internal factors and the use of label information disclosed that gender was positively and significantly correlated with respondents' frequency of label reading to select food based on calorie $(r=0.104, p<0.01)$ and salt $(r=0.097, p<0.01)$ content although both relationships were weak (Table 5).

There was statistically significant positive relationships between respondents' age and the frequency of label reading to select low-calorie $(r=0.154, p<0.01)$, low-sugar $(r=0.111, p<0.01)$ and low-fat $(r=0.088$, $p<$ 0.05) foods. Similarly, self-perceived nutrition knowledge significantly and positively correlated with frequency of reading nutritional labels to select low-calorie $(r=0.099, \mathrm{p}<0.01)$, low-sugar $(\mathrm{r}=0.082$, $\mathrm{p}<0.05)$, low-fat $(\mathrm{r}=0.129, \mathrm{p}<0.01)$, and low-salt $(\mathrm{r}=0.169, \mathrm{p}<0.01)$ foods, even though the relationships were also weak. Meaning, the more a consumer's nutritional knowledge increased the more he/she will frequently read nutritional label to select healthy foods. 
Table 3. Influence of reading nutritional label on respondents’ purchasing decisions.

\begin{tabular}{cccccc}
\hline Purchase intentions & Median & Skewness & Mean & Std. dev. \\
\hline Frequency of nutritional label reading & 3.000 & -0.096 & 3.349 & 1.074 \\
Nutritional label information considered too technical & 3.000 & -0.224 & 2.979 & 1.015 \\
$\quad$ Importance of calorie content for food purchase & 3.000 & -0.059 & 3.003 & 1.248 \\
Frequency of reading nutritional label to choose low-sugar food & 3.000 & -0.142 & 3.151 & 1.175 \\
Frequency of reading nutritional label to choose low-fat food & 3.000 & -0.236 & 3.175 & 1.202 \\
Frequency of reading nutritional label to choose low-salt food & 3.000 & 0.275 & 2.803 & 1.193 \\
\hline
\end{tabular}

Table 4. Determinants of respondents' food choices.

\begin{tabular}{|c|c|c|c|}
\hline Determinants & Responses & & \\
\hline \multirow{2}{*}{ Does taste influences your choice of a cookie or biscuits? } & Yes & 318 & 79.5 \\
\hline & No & 82 & 20.5 \\
\hline \multirow{2}{*}{ Do ingredients used influence your choice of a cookie or biscuits? } & Yes & 235 & 58.8 \\
\hline & No & 165 & 41.2 \\
\hline \multirow{2}{*}{ Does price influences your choice of a cookie or biscuits? } & Yes & 235 & 58.8 \\
\hline & No & 165 & 41.2 \\
\hline \multirow{2}{*}{ Does nutrition label influences your choice of a cookie or biscuits? } & Yes & 141 & 35.2 \\
\hline & No & 259 & 64.8 \\
\hline \multirow{2}{*}{ Does advertisement influences your choice of a cookie or biscuits? } & Yes & 47 & 11.8 \\
\hline & No & 353 & 88.2 \\
\hline \multirow{2}{*}{ Does product name influences your choice of a cookie or biscuits? } & Yes & 38 & 9.5 \\
\hline & No & 362 & 90.5 \\
\hline \multirow{2}{*}{ Does convenience influences your choice of a cookie or biscuits? } & Yes & 67 & 16.8 \\
\hline & No & 333 & 83.2 \\
\hline
\end{tabular}

Percentages represent multiple responses item.

Table 5. Relationship between internal factors and respondents' food choice behaviours.

\begin{tabular}{ccccc}
\hline Variables & Calorie content & Low-sugar food & Low-fat food & Low-salt food \\
\hline Gender & $0.104^{* *}$ & 0.022 & 0.040 & $0.097^{* *}$ \\
Age & $0.154^{* *}$ & $0.111^{* *}$ & $0.088^{*}$ & 0.062 \\
Highest educational level & 0.040 & -0.011 & -0.013 & 0.030 \\
Marital status & 0.067 & 0.032 & -0.019 & 0.015 \\
Employment status & $-0.167^{* *}$ & -0.046 & -0.048 & $-0.117^{* *}$ \\
Health conditions & $-0.094^{* *}$ & -0.067 & -0.041 & $-0.083^{*}$ \\
Nutritional knowledge & $0.099^{* *}$ & $0.082^{*}$ & $0.129^{* *}$ & $0.169^{* *}$ \\
\hline
\end{tabular}

${ }^{* *}$ Correlation is significant at the 0.01 level (2-tailed) $(\mathrm{N}=800) ;{ }^{*}$ Correlation is significant at the 0.05 level (2-tailed). 
Conversely, respondents' employment status negatively and significantly correlated with frequency of label reading to select low-calorie $(r=-0.167, p<0.01)$ and low-salt $(r=-0.117, p<0.01)$ foods. Similarly, health status of respondents' and the frequency of reading nutrition labels to select low-calorie $(r=-0.094, p<0.01)$ and low-salt $(r=-0.083, p<0.05)$ food products were negatively and significantly correlated. Highest educational level and marital status of respondents on the other hand, had no statistical significant relationship with the frequency of reading labels to select food based on the negative nutrition factors.

The comparative analysis of the influence of label usage to select healthy packaged foods by the respondents did not present any statistically significant difference between male and female respondents with regard to lowsugar, low-fat and low-salt. However, with respect to calorie content, there was a statistically significant difference in male respondents food purchase behaviour (Mean $=2.877$, Std. Dev. $=1.219)$ and that of their female counterparts (Mean $=3.222$, Std. Dev. $=1.212)$, $[\mathrm{t}=-2.822, \mathrm{df}=398, \mathrm{p}=0.005]$. Female respondents (eta square $\left(\eta^{2}\right)=0.020$ ) were apt to select low-calorie foods than the males (Table 6). Deviation and $\eta^{2}=$ eta square.

Table 6. Gender differences in the food choices of respondents.

\begin{tabular}{cccccccc}
\hline Content of food & Gender & $\mathrm{N}$ & Mean & Std. dev. & t-value & Sig. & $\eta^{2}$ \\
Calorie & Male & 220 & 2.877 & 1.219 & -2.822 & 0.005 & 0.020 (Weak) \\
& Female & 180 & 3.222 & 1.212 & & 0.882 \\
Low-sugar & Male & 220 & 3.204 & 1.037 & 0.149 & & \\
& Female & 180 & 3.188 & 1.061 & & \\
Low-fat & Male & 220 & 3.222 & 1.072 & & \\
& Female & 180 & 3.211 & 1.024 & & \\
Low-salt & Male & 220 & 2.613 & 1.025 & -0.768 & 0.443 \\
& Female & 180 & 2.694 & 1.073 & &
\end{tabular}

Source: Field data, 2014. $(\mathrm{N}=400)$. Where $\mathrm{N}=$ sample size, Std. dev. = standard.

\section{Discussion}

Over-nutrition related diseases currently exceed that of under-nutrition, which calls for concern [13]. This trend has been attributed to the consumption of foods high in calories, fats, sugar and salt, which is a characteristic of urbanity. There is the need for food science and nutrition to adopt strategies that may help to decrease the risks of diet-related non-communicable diseases and obesity. In some European countries, nutrition labelling of packaged foods has been a major tool assisting consumers to make nutritionally appropriate and healthy food choices [7]. This investigation aimed at assessing nutrition labelling awareness, understanding of nutrition information, and whether information on calorie, fat, sugar and salt content enabled consumers in Shenyang, China, to make healthy food choices. The study mainly focused on self-reported behaviour even though respondents' self-perceived understanding of some nutritional claims was verified. Purchase decisions based on four negative nutrition factors was conceptualized as respondents' food behaviours.

The spread and the random selection of the studied sample has a positive impact in getting responses that may be representative of consumer's living in Shenyang, China. In addition, the sample comprised almost equal representation of both genders and this made it possible to explore the impact of gender and the use of the negative nutrition factors. The sample also included consumers across all age groups, of different marital and health statues and with different levels of education and perceived nutrition knowledge, which presents a fair representation of possible market segments.

Over three quarters of respondents indicated that they "somehow" understand nutrition information available on labels (Table 1), an assertion that was supported by respondents' interpretation of nutrition claims that were presented them. This finding is consistent with the conclusion drawn from a survey by the AFIC [9] on consumer responses to nutrition information and health claims on packaged foods. The authors reported that even though the Chinese and Malaysian consumers supported the provision of nutrition information on labels, they 
acknowledged the fact that they did not have the capacity to understand such information as indicated by their self-rated low knowledge in nutrition.

In a study to ascertain Australian consumers' perception about fat and whether fat claims on food labels influenced their food choices, the authors [14] reported that while some of the participants misinterpreted a low-fat claim a as a leeway to consume more of a product, others admitted consuming more of a product because they bore a low or reduced fat claims. Thus, misinterpretation of nutrition claims on food labels could impact on the amount of a product, and subsequently nutrient, a consumer may eat. In this study, more than half of the respondents interpreted "salt free claim" to mean that the product did not have any salt and a preponderant percentage (91.4\%) took "reduced sugar" to mean $20 \%$ or less sugar (Table 2).

The participants in the Australian study noted their preference for "X\% fat free" claims than claims of "X\% less fat", because they found it easier to measure the former against the NIP, whereas it is uncertain the relevant products against which the latter could be compared [14]. It has been found that consumers generally tend to be confused about comparative nutrition claims, which make the overall nutritional value of products quite unclear [15]. It has been observed in the US that percentage reduction of energy intake from fat for 25 years for instance, has not had any impact on obesity rates, a condition that has been attributed to lack of understanding of less quantitative claims, such as "low fat" and "fat free" leading to over consumption of products without due regard to the their total energy content and other nutritional characteristics [16].

On the other hand, other authors [11] maintain that consumers, especially those with restricted diets, are usually guided by label claims such as "low sodium" or "no sodium" to more easily identify foods that are appropriate and particularly suitable to them. Thus, this situation warrants further investigation. More Chinese consumers should be presented with all-inclusive nutrition claims to interpret. Furthermore, they should be provided with products bearing different types of nutrition claims to evaluate their appropriateness and suitability, and as to whether they can eat more of such products than the regular equivalent to provide more conclusive evidence.

Knowledge about RDA and its application is important for label usage as it guides consumers to fit nutrients consumed from packaged food into their overall daily diet. More than half of respondents in this study did not understand the meaning of RDA, thoughtless of selecting foods to reflect their daily nutrient needs and two thirds had no idea about their daily nutrient needs. In a similar study on reading and the use of food labels by Indian consumers [17] some of the consumers suggested benchmarks to facilitate the understanding of RDA and majority of them accordingly computed DVs with given information on serving size. Misconceptions about DVs have been reported in studies conducted in the USA, with consumers' indicating their preference for amountper-serving information expressed in metric units (grams) over per cent DV [7].

More than two thirds of respondents in this study did not believe that nutrition claims are truthful, even though more than three quarters of respondents still reported reading nutrition label. Nonetheless, such uncertainty about label information could discourage consumers from using them [18]. The survey on Chinese and Malaysian consumers' responses to nutrition information on nutrition labels indicated that consumers' confidence in label claims may be enhanced with an endorsement by a third party, such as a national regulatory authority or internationally recognized organization [7]. It has also been shown that consumers tend to believe health claims that are brief and placed in the front of packages than when they are lengthy and not readily noticed [19].

A significantly healthier consumption level with regard to total calories, total fat, saturated fat, cholesterol, sodium, dietary fibre and sugar was observed in those who read labels compared to non-users, when Ollberding et al investigated the reading habits of American consumers to determine the effect of reading food label information on their dietary behaviour [20]. On the other hand, recent report on food and health survey by IFIC shows that taste and price continue to dictate the food choices of Americans more than healthiness [18]. Although respondents in this study reported using nutrition information on calorie, fat, sugar and salt frequently to evaluate the overall quality of a product, the presence of these factors was not the major determinant of their food choices. Furthermore, salt content of packaged foods rarely affected choices made by respondents.

Consistent with the findings of a qualitative data from AC Nielsen [7] on out-of home eating choices and attitudes toward weight management, respondents in this study cited taste as the most important factor in determining the choice of biscuits/cookies. The food choices of the survey respondents sampled from 12 Asian countries were mainly motivated by taste, convenience and what was socially accepted as food while nutrition claims were considered to be of secondary importance. It has also been found in other studies that consumers who value taste were less likely to read and apply nutrition information [21]. Snacks usually contain large amounts of the 
negative nutrition factors especially trans-fats to improve flavour and extend shelf life [22]. Labelling of Chinese packaged products concentrate on vitamin, mineral, dietary fibre and nutrition health claim, which has been noted as representing the Chinese population's diet-related health perspectives [11]. On the contrary, less attention is devoted to calories, fats, sugars, sodium and trans-fats, even though these negative factors are the nutrients responsible for the development of chronic diseases [23]. The absence of such information on labels makes them inaccessible and could explain why consumers do not often use them.

Evidence suggests that education intervention leads to increase in the average scores of knowledge and helps to form correct health concepts leading to improved dietary habits [24] [25]. In this study, highest level of formal education did not have any significant effect on respondent's food choices while nutrition knowledge positively influenced the choice of low-calorie, fat and sugar foods. It has been observed that high level of nutrition awareness among consumers causes industries to display nutrition claims that meet public demands and guides policy makers to manage nutrition labelling [26] [27]. This is very crucial for China where nutrition labelling has just begun, nutrition awareness is low and consumption of packaged food is very high.

Even though respondents read nutrition information regarding the negative nutrition factors in food, the extent to which they were affected by these factors was demographic dependent. Age positively affected food choices while respondents without any health condition paid less attention to the calorie and salt content of packaged foods they purchased. This suggests that healthy consumers were not engaged in risk avoidance approach to food selection. It is important to encourage consumers to engage in healthy dietary practices that help promote and facilitate wellness. This could help control the incidence of chronic diseases such as hypertension and diabetes as well as their management.

Although food purchase behaviour of respondents were generally not affected by the salt content of food, females were more mindful of the salt content of foods than males. Current literature suggests that people all around the globe are consuming sodium far above daily requirements, particularly among Asian countries [28]. Again, female respondents paid more attention to the calorie content of food, which coincides with the increased importance given to decrease in weight by women. Evidence suggests that females are mindful about their health issues rather than males [29].

\section{Conclusions}

Nutritional labelling in China is recent and labelling of some nutritional factors still remains voluntary. This study brings to the fore consumers' understanding and use of nutritional claims on food labels. The findings suggested a low nutritional labelling awareness among respondents even though majority of the respondents were well educated. The findings further indicate that consumers do not always read nutrition labels and over consumption of nutrients from packaged foods stems from misunderstanding of label information. Moreover, other competing factors such as taste and price as well as scepticism about label claims may prevent consumers from reading and applying nutrition information. To a large extent, the effectiveness of nutrition labels depends on consumers' perceptions and beliefs about the use of these labels. Much effort in raising public nutritional awareness and demystify consumers' perception about label claims and health perspectives, which may have cultural undertones, is needed to modify food behaviours and also engender consumer confidence.

The results of this study reflect the use of nutrition claims and food choice behaviour of consumers in Shenyang, China. Caution is needed in generalizing the findings to the entire Chinese population since it is an exploratory study. Further research on more Chinese consumers is needed to determine whether or not the results obtained in this study apply to the general Chinese consumer population, since different consumers may exhibit varying levels of knowledge with regard to nutrition labels, and may exhibit varying food choice behaviours.

\section{Acknowledgements}

This research was sponsored by the PhD-scholarship from the Major Project of Liaoning Provincial Science and Technology Foundation and the Top Talent Fund of Shenyang Agricultural University. The authors wish to thank all consumers who participated in the study.

\section{References}

[1] World Health Organization (2015) Healthy Living. http://www.who.int/dietphysicalactivity/publications/en/ 
[2] Withrow, D. and Alter, D.A. (2011) The Economic Burden of Obesity Worldwide: A Systematic Review of the Direct Costs of Obesity. Obesity Review, 12, 131-141. http://dx.doi.org/10.1111/j.1467-789X.2009.00712.x

[3] Campos, S., Doxey, J. and Hammond, D. (2011) Nutrition Labels on Pre-Packaged Foods: A Systematic Review. Public Health Nutrition, 14, 1496-1506. http://dx.doi.org/10.1017/S1368980010003290

[4] Brandt, M.., Moss, J. and Ferguson, M. (2009) The 2006-2007 Food Label and Package Survey (FLAPS): Nutrition Labelling, Trans Fat Labelling. Journal of Food Composition and Analysis, 22, S74-S77. http://dx.doi.org/10.1016/j.jfca.2009.01.004

[5] LeGault, L.A., et al. (2004) 2000-2001 Food Label and Package Survey: An Update on Prevalence of Nutrition Labelling and Claims on Processed, Packaged Foods. Journal of American Dietetic Association, 104, 952-958. http://dx.doi.org/10.1016/j.jada.2004.03.024

[6] Food Standards Australia New Zealand (FSANZ) (2008) Assessment of 2006 Labels for Key Mandatory Labelling Elements for Consistency against Labelling Provisions (Phase 2 Report), 18, FSANZ, Canberra.

[7] Wills, J.M., Schmidt, D.B., Pillo-Blocka, F. and Cairns, G. (2009) Exploring Global Consumer Attitudes toward Nutrition Information on Food Labels. Nutrition Reviews, 67, 102-106. http://dx.doi.org/10.1111/j.1753-4887.2009.00170.x

[8] Sidiga, W. (2012) Awareness of Food Labelling among Consumers in Groceries in Al-Ain, United Arab Emirates. International Journal of Marketing Studies, 4, 1.

[9] Kempen, E.L., Muller, H., Symington, E. and van Eeden, T. (2012) A Study of the Relationship between Health Awareness, Lifestyle Behaviour and Food Label Usage in Gauteng. South African Journal of Clinical Nutrition, 25, 15-21.

[10] Ministry of Health of the People's Republic of China (2008) Regulation of Food Labelling.

[11] Wang, S., et al. (2011) The Changes of Nutrition Labelling of Packaged Food in Hangzhou in China during 2008-2010. PLoS ONE, 6, e28443.

[12] Lv, J., et al. (2011) A Survey of Nutrition Labels and Fats, Sugars, and Sodium Ingredients in Commercial Packaged Foods in Hangzhou, China. Public Health Reports, 126, 116-122.

[13] Weaver, C.M., et al. (2014) Processed Foods: Contributions to Nutrition. American Journal of Clinical Nutrition, 99, 1525-1542. http://dx.doi.org/10.3945/ajcn.114.089284

[14] Chan, C., Patch, C. and Williams, P. (2005) Australian Consumers Are Sceptical about but Influenced by Claims about Fat on Food Labels. European Journal of Clinical Nutrition, 59, 148-151. http://dx.doi.org/10.1038/sj.ejcn.1602038

[15] Andrews, J., Burton, S. and Netemeyer, R. (2000) Are Some Comparative Nutrition Claims Misleading? The Role of Nutrition Knowledge, Ad Claims Type and Disclosure Conditions. Journal of Advertising, 29, 29-42. http://dx.doi.org/10.1080/00913367.2000.10673615

[16] Willett, W. (1998) Is Dietary Fat a Major Determinant of Body Fat? American Journal of Clinical Nutrition, 67, 556S562S.

[17] Singla, M. (2010) Usage and Understanding of Food and Nutritional Labels among Indian Consumers. British Food Journal, 112, 83-92. http://dx.doi.org/10.1108/00070701011011227

[18] International Food Information Council Foundation (2012) Food \& Health Survey: Consumer Attitudes toward Nutrition, Food and Health. http://www.foodinsight.org

[19] Wansink, B. (2003) How Do Front and Back Package Labels Influence Beliefs about Health Claims? Journal of Consumer Affairs, 37, 305-316. http://dx.doi.org/10.1111/j.1745-6606.2003.tb00455.x

[20] Ollberding, N.J., Wolf, R.L. and Contento, I.R. (2010) Label Use and Its Relationship to Dietary Intake among US Adults. Journal of American Dietetic Association, 110, 1233-1237. http://dx.doi.org/10.1016/j.jada.2010.05.007

[21] Drichoutis, A.C., Lazaridis, P. and Nayga, R.M. (2005) Nutrition Knowledge and Consumer Use of Nutritional Food Labels. European Review of Agricultural Economics, 32, 93-118. http://dx.doi.org/10.1093/erae/jbi003

[22] Sonia Y.A., et al. (2009) Cholesterol Control beyond the Clinic: New York City's Trans-Fat Restriction. Annals of Internal Medicine, 151, 129-134. http://dx.doi.org/10.7326/0003-4819-151-2-200907210-00010

[23] Barzegari, A., Ebrahimi, M., Azizi, M. and Ranjbar, K. (2011) A Study of Nutrition Knowledge, Attitudes and Food Habits of College Students. World Applied Sciences Journal, 15, 1012-1017.

[24] Heimbach, J.T. and Stokes, R.C. (1982) Nutrition Labelling and Public Health: Survey of American Institute of Nutrition Members, Food Industry, and Consumers. American Journal of Clinical Nutrition, 36, 700-708.

[25] Sharma, S.V., Gernand, A.D. and Day, R.S. (2008) Nutrition Knowledge Predicts Eating Behaviour of All Food Groups Except Fruits and Vegetables among Adults in the Paso Del Norte Region: QuéSabrosa Vida. Journal of Nutrition Education and Behaviour, 40, 361-368. http://dx.doi.org/10.1016/j.jneb.2008.01.004

[26] Lalor, F., Kennedy, J., Flynn, M.A.T. and Wall, P.G. (2010) A Study of Nutrition and Health Claims-A Snapshot of 
What's on the Irish Market. Public Health Nutrition, 13, 704-711. http://dx.doi.org/10.1017/S1368980009991613

[27] Legislative Council of Hong Kong (2008) The Food and Drugs (Composition and Labelling Amendment: Requirement for Nutrition Labelling and Nutrition Claim) Regulation 2008.

[28] Ian, J., et al. (2009) Salt Intakes around the World: Implications for Public Health. International Journal of Epidemiology, 38, 791-813. http://dx.doi.org/10.1093/ije/dyp139

[29] Hendrie, G.A., Coveney, J. and Cox, D. (2008) Exploring Nutrition Knowledge and the Demographic Variation in Knowledge Levels in an Australian Community Sample. Public Health Nutrition, 11, 1365-1371.

http://dx.doi.org/10.1017/S1368980008003042 